
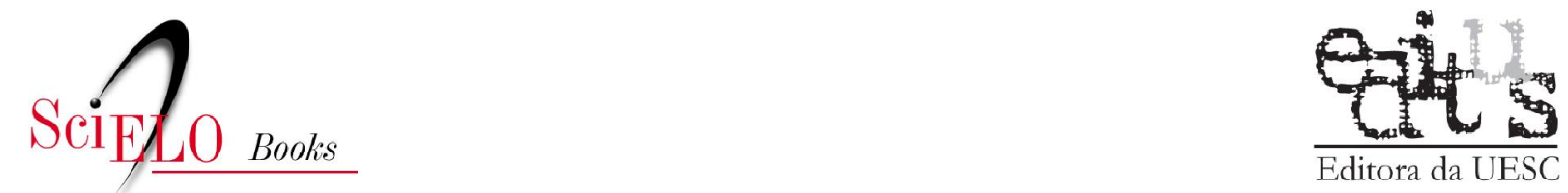

Editora da UESC

\title{
10 Plano de recuperação de áreas degradadas (PRAD)
}

\author{
Danilo Sette de Almeida
}

SciELO Books / SciELO Livros / SciELO Libros

ALMEIDA, DS. Plano de recuperação de áreas degradadas (PRAD). In: Recuperação ambiental da Mata Atlântica [online].3rd ed. rev. and enl. Ilhéus, BA: Editus, 2016, pp. 140-158. ISBN 978-85-

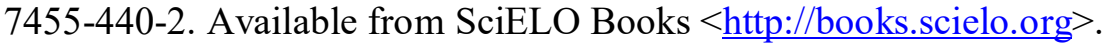

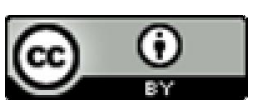

All the contents of this work, except where otherwise noted, is licensed under a Creative Commons Attribution 4.0 International license.

Todo o conteúdo deste trabalho, exceto quando houver ressalva, é publicado sob a licença Creative Commons Atribição 4.0.

Todo el contenido de esta obra, excepto donde se indique lo contrario, está bajo licencia de la licencia $\underline{\text { Creative }}$ Commons Reconocimento 4.0. 


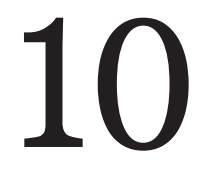

\section{PLANO DE RECUPERAÇÃO DE ÁREAS DEGRADADAS (PRAD)}




\subsection{Definições gerais}

$\mathrm{P}$ RAD significa plano ou projeto de recuperação de áreas degradadas, que tem como objetivo principal criar um roteiro sistemático, contendo as informações e especificações técnicas organizadas em etapas lógicas, para orientar a tecnologia de recuperação ambiental de áreas degradadas ou perturbadas para alcançar os resultados esperados. Segundo a Fundação para Conservação e a Proteção Florestal do Estado de São Paulo (2004), o projeto técnico é um instrumento de planejamento, execução e avaliação. O PRAD teve sua origem no artigo 225, da Constituição Federal de 1988, e no Decreto-Lei n. 97.632/89, que regulamentou a Lei n. 6.938/81, obrigando a recuperação da área degradada como parte do Relatório de Impacto Ambiental, podendo ser empregado de forma preventiva ou corretiva, em áreas degradadas por ações de mineradoras. No início, o PRAD era aplicado apenas na atividade mineradora, na década de 1990, foi estendido como forma de condicionante e ajustes de conduta ambiental para outras atividades degradadoras, sendo incorporado como um programa complementar da maioria dos Estudos de Impacto Ambiental e Relatórios de Impacto Ambiental e em Termos de Ajuste de Conduta (TAC), firmados entre empresas e o Ministério Público. Grande parte dos trabalhos de recuperação ambiental, originários de PRAD, tem origem nas imposições da legislação brasileira. Mais recentemente, outro dispositivo legal, a Instrução normativa n. 4, de 13 de abril de 2011, estabelece procedimentos para elaboração do PRAD ou Área Alterada. Esta instrução traz como anexos Termos de Referência, e distingue dois tipos de PRAD (PRAD e PRAD simplificado), que são aplicados conforme cada caso especificado na norma. Na instrução é determinado que "o PRAD deve reunir informações, diagnósticos, levantamentos e estudos que permitam a avaliação da degradação ou alteração e a consequente definição de medidas adequadas à recuperação da área".

O PRAD é conduzido conforme objetivos discutidos com o proprietário (ou proponente), alinhados com o técnico responsável pelo projeto e acompanhamento, conforme Instrução normativa n. 4, de 13 de abril de 2011, o proprietário deve assinar também o "Termo de Compromisso de Reparação de Dano Ambiental”, que será anexado ao PRAD a ser apresentado. 
Uma observação a ser considerada é que uma parte considerável dos PRAD, apresentados e aprovados por órgãos ambientais, na prática, não são implantados. Existe uma necessidade dos órgãos ambientais estaduais e municipais acompanharem a implantação destes PRAD.

Hoje, normalmente, existem, em vários estados, roteiros ou termos de referência para elaboração de PRAD, neste capítulo, mostramos um roteiro mais geral e mais utilizado de forma normal no Brasil. É recomendado que um projeto técnico contivesse os seguintes itens básicos: introdução, objetivos, metas, metodologia, sistema de monitoramento e avaliação, cronograma de execução, recursos materiais, humanos e financeiros, e anexos (FUNDAÇÃO PARA CONSERVAÇÃO E A PROTEÇÃO FLORESTAL DO ESTADO DE SÃO PAULO, 2004).

\subsection{Procedimentos e métodos para elaboração de PRAD}

\subsubsection{Considerações e planejamento inicial}

O processo de recuperação ambiental é complexo, requerendo tempo, recursos (dinheiro, mão de obra e tecnologia) e conhecimento dos diversos fatores relacionados à área a ser recuperada, como as características do solo, da água, da fauna, da flora e as modificações inerentes ao processo que ocasionam (ou ocasionarão) o distúrbio. O PRAD deve ter inicialmente seus objetivos bem definidos, ajustando variáveis como: as necessidades legais, desejo do proprietário do terreno, aspectos sociais e econômicos. Nunca esquecendo de que o objetivo principal é promover a recuperação ambiental de uma área degradada.

O planejamento inicial prevê a necessidade da confecção de um roteiro que busque a solução mais rápida, mais eficiente e mais econômica para se recuperar as áreas degradadas faz-se necessário conhecer o passado, analisar o presente e planejar o futuro das áreas a reabilitar. O planejamento deve ser com uma visão de longo prazo. O processo de planejamento deve ser realizado, projetando-se em longo prazo e contemplando sempre uma visão global do problema. Os "pacotes" e "receitas" generalistas não funcionam no caso de recuperação, cada situação específica deve receber um 
tratamento adequado. As etapas, aqui mostradas, compõem apenas um roteiro bem simples e básico, que pode ser adaptado para cada caso específico.

Hoje, um PRAD deve considerar em seu escopo, além dos aspectos ambientais, as variáveis sociais e ambientais, envolvidas no processo de recuperação. Os atores sociais (população que, originalmente, ocupava a área degradada e entorno, incluindo seus valores e interesses) assim como a atividade econômica, que era desenvolvida na área antes da intervenção (impacto) ambiental, devem ser considerados.

Uma das etapas mais importantes a ser considerada é o diagnóstico que permite o conhecimento da amplitude dos problemas ambientais, sociais e econômicos envolvidos no processo de recuperação ambiental da área e respectivo PRAD. O diagnóstico prévio de aspectos ambientais (biológicos) e socioeconômicos permite que se estabeleçam metas para a recuperação ambiental, dando mais consistência ao PRAD e a seu processo de implementação.

O sucesso e a garantia de implantação do projeto de recuperação são oriundos do gerenciamento responsável dos recursos e das atividades envolvidas, que vão garantir a implantação do projeto, a responsabilidade técnica dos autores dos projetos que devem, obrigatoriamente, acompanhar tecnicamente a implantação e manutenção do PRAD. Em empresas que possuem as respectivas áreas ambientais, este projeto e acompanhamento poderão ser feitos por técnico do próprio quadro da empresa, porém a maioria dos PRAD é elaborada e supervisionada por profissionais terceirizados (consultores).

Todo planejamento para implantação do PRAD não deve ser voltado somente para os interesses e necessidades do empreendedor, mas também para o sucesso do plano, considerando os aspectos biológicos, físicos, socioculturais, econômicos, políticos, na qual a área objeto do PRAD está inserida.

Nesta primeira etapa, devemos considerar as pretensões e objetivos do proprietário com referência ao destino da futura área, aspectos e obrigações legais, envolvidos com o problema, e realizar um levantamento do histórico de ocupações da área a ser recuperada (revisão bibliográfica e fotográfica sobre a região, histórico de utilização da área e informações sobre a área antes da degradação - vegetação, fauna, hidrografia, clima, atividades antrópicas). 
10.2.2 Identificação dos agentes de degradação

Fazer o levantamento dos agentes de degradação que atuaram e ainda agem sobre a área a ser recuperada, proporcionando a continuidade da degradação dos recursos naturais.

\subsubsection{Delimitação das áreas de influência}

Delimitar a área de influência direta (que está degradada), na qual devemos concentrar os trabalhos de diagnóstico e estudos referentes ao meio físico e biológico (estudo do substrato atual e área de influência indireta, o entorno), que deve ser considerada com referência aos aspectos socioeconômicos, além dos biológicos e físicos de referência (áreas similares à original que ainda permanecem intactas).

\subsubsection{Avaliação do grau de degradação}

Devem ser avaliados o estado atual do substrato (solo) da área e a capacidade de regeneração biótica da vegetação.

\subsection{Elaboração do projeto de recuperação - roteiro básico}

10.3.1 Parte introdutória

a. Introdução - resumo geral do PRAD, onde são citados o estado ambiental da área degradada, os objetivos e as metas do projeto.

b. Objetivos - descrição dos objetivos gerais e específicos esperados com a implantação do PRAD.

c. Metas - descrição das metas pretendidas.

d. Caracterização da região - esta parte deve conter uma breve caracterização biológica, física e climática da região, com enfoque na propriedade onde está inserida a área degradada. Informações sobre o clima regional, variação anual de temperatura e precipitação, tipos de solos, classificação e caracterização da vegetação, malha viária e uso atual predominante. Estas características devem ser 
descritas superficialmente neste item inicial e detalhadamente na fase de diagnóstico da área a ser recuperada.

e. Equipe técnica do PRAD - descrição da equipe técnica responsável pela elaboração do PRAD. Conforme estado e grau de degradação, podemos ter um PRAD elaborado por um só profissional ou por uma equipe técnica. Por exemplo, citamos uma atividade de mineração, quando temos necessidade de Geólogo/Engenheiro Florestal/ Agrônomo/Biólogo complementarmente.

\subsubsection{Caracterização do Empreendimento}

a. Informações Gerais - nome, endereço, CEP, telefone, área degradada, atividade e substância retirada, responsável técnico pela atividade degradadora inicial.

b. Licenciamento ambiental da atividade inicial - relação de todas as licenças ambientais existentes no empreendimento e respectivos condicionantes. Deve conter licenciamentos ambientais de funcionamento e supressão de vegetação.

c. Localização e acesso - deve conter roteiro de acesso ao empreendimento, além de croqui ou mapa com localização das estradas de acesso, e demarcação das áreas a serem exploradas.

d. Área degradada - área requerida, área prevista inicialmente, área com outras atividades, área de serviço de apoio, área total efetivamente utilizada.

e. Mão de obra - pessoas envolvidas em cada atividade na exploração da área.

f. Período de funcionamento - horário de funcionamento da atividade exploratória.

\section{g. Informações sobre a atividade exploratória}

i) Reservas

ii) Estimativa de produção (estoque de terra, argila, minério etc.).

iii) Produção - previsão de produção periódica e total da área.

iv) Tempo de utilização da área a ser explorada - tempo que irá durar a atividade. 
v) Métodos utilizados - descrição de qual metodologia a ser empregada em cada processo.

vi) Equipamentos a serem utilizados - relação de equipamentos e quantidades a serem utilizados na atividade exploratória.

vii) Descrição do processo de beneficiamento - descrição do processo final de beneficiamento, principalmente em pedreiras e minerações.

viii) Controle de poeira e ruído - outros tipos de poluição que devem ter controle previsto no PRAD. Geralmente, o trânsito intenso de caminhões e a geração de poeiras requerem um sistema de irrigação de estradas.

ix) Bota-fora - área destinada a depósito de estéreis e restos de construção do empreendimento. Esta área receberá no PRAD um tratamento especial para recuperação. Deve ser observada a composição do bota-fora, fatores, como a presença de metais pesados, requerem técnicas complementares de recuperação e segurança.

x) Ações contra erosão - medidas como a construção de sistema de drenagem, construção de canaletas, escadas de água, caixas e outros.

xi) Segurança do trabalho e placas de sinalização previsão da colocação de placas, e técnicas de segurança a serem adotadas.

xii) Armazenamento da camada superficial do solo - deve ser previsto o local de armazenamento da camada superficial do solo, esta operação é muito importante para o processo de recuperação ambiental da área degradada.

\subsection{Diagnósticos Ambientais}

Esta etapa compreende todas as observações e levantamentos de campo, como:

a. identificação e avaliação dos impactos;

b. mapeamento das diferentes unidades de paisagem; 
c. caracterização física e química (limitações dos solos, nível de fertilidade) dos solos, análises biológicas e químicas da água;

d. estudos faunísticos - grupos de espécies bioindicadoras e dispersores; relação flora/fauna, dispersores, polinizadores;

e. estudos da flora - observações de campo (curto prazo) e levantamentos florísticos e fitossociológicos (longo prazo).

Destacamos a importância do conhecimento dos estratos herbáceo, arbustivo e arbóreo, pois, em função do estágio de degradação da área a ser recuperada, faz-se necessária a recomposição a partir de estratos inferiores (herbáceos). Caso a área já se encontre degradada, temos de tomar como referências áreas vizinhas similares para estudos de vegetação, solos, fauna e outros necessários.

10.4.1 Caracterização do meio físico

a. Geologia e Geomorfologia - classificação e caracterização geológica da área a ser explorada e vizinhança.

b. Clima - informações gerais sobre o clima como precipitação média mensal, relação e média das temperaturas, velocidade dos ventos etc. Grande parte destas informações pode ser obtida nos órgãos estaduais, ligados à Secretaria de Agricultura e Meio Ambiente, e federais (de pesquisa como EMBRAPA, CEPLAC) que, muitas vezes, possuem estações meteorológicas e têm séries históricas de dados climáticos.

c. Solos - tipos de solos existentes na área explorada.

d. Hidrologia e qualidade das águas superficiais e subterrâneas - descrição dos recursos hídricos, incluindo bacia hidrográfica na qual a área a ser explorada está incluída.

\subsubsection{Caracterização do meio biótico}

i) Flora - o ideal é a descrição da composição florística, os estudos fitossociológicos são importantes para subsídios aos projetos de recuperação ambiental. 
ii) Fauna - descrição da fauna presente na área e vizinhança. Vai subsidiar a possível formação de corredores que pode ser obtida com a recuperação ambiental da área degradada.

10.4.3 Caracterização do meio socioeconômico

Estudos relativos às características sociais e econômicas da atividade, e da vizinhança (entorno).

\subsection{Plano de recuperação das áreas degradadas (Reconstituição do meio ambiente)}

a. Impactos ambientais negativos do empreendimento - descrição dos impactos, caso exista um EIA/RIMA, este poderá servir de referência. Pode ser feito na forma de listagem de impactos ou matriz de impactos. As medidas mitigadoras de cada impacto devem fazer parte deste PRAD.

b. Processo de degradação - desmatamento, decapeamento, utilização de explosivos, ruídos e poeira, emissão de poeira, ruídos, bota-fora.

c. Recomposição topográfica e paisagística - tratos na superfície do terreno evitando declives abruptos e taludes inclinados.

d. Tratos da superfície final - preparo do solo para etapas finais da recuperação, isto é, revegetação.

e. Obra de Engenharia - em áreas inclinadas, é indispensável, para contenção do processo erosivo, a instalação de uma rede de drenagem. Deve ser observada a compatibilidade do clima e do solo com as obras civis e revegetação previstas. Construção de barragens de rejeitos é necessária em alguns casos, como, por exemplo, áreas inclinadas com solo arenoso, certas áreas mineradas etc.

f. Relocação da camada fértil do solo - a camada superficial do solo, que é retirada e armazenada no início do empreendimento, deve ser novamente distribuída na superfície da área a ser recuperada.

g. Redução do grau de compactação do solo - etapa que deve ser prevista no caso da existência de grande compactação 
dos solos, devido, principalmente, ao trânsito de máquinas e caminhões.

h. Correção da fertilidade do solo - deve conter as análises química e física, quando as condições do solo estiverem muito alteradas quanto à compactação e ao adensamento do substrato (solo). Compreende as recomendações sobre aplicação de corretivos e de adubação.

i. Estratégias (metodologia) para recomposição da vegetação - envolve todo trabalho de restabelecimento da vegetação original, compreendendo etapas como: definição dos métodos biológicos de recuperação de áreas degradadas, seleção das espécies a serem utilizadas, definição dos modelos de recuperação a serem empregados, técnicas de preparo da área, manutenção, etc.

Este item deve conter a descrição detalhada de:

- Especificações técnicas - espaçamento (tomado também com base nos estudos fitossociológicos), medidas das covas (berço), necessidade de adubação, seleção de espécies, definição das estratégias de recuperação a serem utilizadas.

- Operações a serem realizadas com respectivos rendimentos operacionais - limpeza da área (manual ou mecanizada), coroamento, coveamento, plantio, adubação.

- Necessidade e quantificação de equipamentos de proteção individual (EPI), ferramentas, máquinas.

- Insumos necessários - é a relação das espécies a ser utilizada (espécies nativas selecionadas com base nos estudos florísticos e resultados fitossociológicos, separando -os em grupo ecofisiológicos, contendo nomes vulgares, nomes científicos, família), adubos necessários (fórmulas e quantidades), iscas formicidas e calcário.

j. Custos e produtividade - nesta parte, devem constar os custos referentes a cada operação programada, assim como rendimentos operacionais de cada operação prevista no projeto. Estas informações técnicas, operacionais e financeiras são importantes referências para orientação de futuros projetos de recuperação de áreas degradadas. Portanto é necessário programar temporariamente os custos do projeto, ajustando, com o cronograma operacio- 
nal, o desembolso necessário para implantação do PRAD.

k. Cronograma de execução - o cronograma serve como referência temporal para o acompanhamento técnico e orçamentário de liberação de recursos de todas as etapas previstas no projeto de recuperação. Todo suporte técnico, administrativo e financeiro é baseado no cronograma. No caso de um projeto de recuperação ambiental, não podemos deixar de considerar, entre outros, os fatores climáticos e sazonalidade regional da mão de obra.

1. Sistema de monitoramento e avaliação - a etapa de monitoramento compreende o acompanhamento contínuo, quando é avaliado o desempenho da estratégia de recuperação ambiental utilizada, permitindo eleger as práticas de recuperação ambiental mais adequadas para alcançar os objetivos predeterminados para a reabilitação do ambiente. Devem ser tomadas como referência as condições iniciais (referências iniciais antes da recuperação e logo após a recuperação) e o objetivo final que pretendemos alcançar, por exemplo, em uma área de floresta tropical, onde a área degradada era ocupada antes por floresta tropical, nosso objetivo é recuperar este ecossistema. O conjunto de variáveis biológicas, químicas e físicas deve ser utilizado de maneira sistemática, ao longo do tempo. Observamos a importância do monitoramento ambiental nos processos de tomada de decisões gerenciais e técnicas, envolvidas no processo de implantação de PRAD e recuperação ambiental da área, os resultados com certeza vão indicar novas práticas a serem adotadas na área em recuperação.

Para o monitoramento, é utilizada uma série de indicadores como:

i) Meio físico - geralmente são monitoradas as propriedades químicas dos solos, como $\mathrm{pH}$ em água, carbono orgânico total, $\mathrm{P}, \mathrm{K}$, disponível, $\mathrm{Ca}, \mathrm{Mg}$ e Al trocáveis, soma de bases e capacidade de troca de cátions efetiva e a $\mathrm{pH}$ 7. Outras análises específicas para a área recuperada podem ser utilizadas. Estas análises podem ser realizadas semestral ou anualmente. 
- Variáveis químicas dos solos - quantificação da matéria orgânica e a condutividade elétrica da solução do solo.

- Variáveis físicas - estrutura, densidade do solo, resistência ao penetrômetro, capacidade de retenção de água e profundidade média do sistema radicular das espécies de maior presença.

ii) Da mesma maneira, pode ser monitorada a qualidade da água, principalmente se a área estiver próxima a algum curso de água. Esta variável poderá ser utilizada pelo acompanhamento de variáveis químicas da água - O.D. - oxigênio dissolvido, turbidez, nitrito, fosfato, $\mathrm{pH}$. Estas análises podem ser realizadas semestral ou anualmente.

m. Meio biótico - deve ser acompanhada, através da implantação de parcelas permanentes, a evolução da sucessão ecológica da vegetação, isto é, espécies presentes e novas espécies desenvolvidas na área (aumento da diversidade), permitindo comparações com a vegetação primitiva. Indicadores como densidade de plantas por área, regeneração natural, riqueza de espécies botânicas, índices de diversidade e de similaridade entre áreas, além da produtividade em termos de crescimento da biomassa acima do solo, crescimento em altura e diâmetro das espécies presentes são bons indicadores da evolução do processo de regeneração natural.

Também podem ser feitos monitoramentos da fauna silvestre que pode ser monitorada através de grupos bioindicadores como avifauna ou formigas. Normalmente as análises do meio biótico (flora e fauna) podem ser realizadas anual ou bianualmente.

n. Manutenção de plantios - talvez, uma das etapas mais importantes, em todo processo de recuperação de uma área degradada, seja a manutenção da vegetação implantada. Em função, principalmente da presença de plantas invasoras na área (que vão competir ou até mesmo matar as mudas das espécies introduzidas), deve 
ser planejada a frequência das manutenções. Em áreas antes ocupadas por determinados tipos de gramíneas, como braquiárias ou colonião, por exemplo, se faz necessário, na maioria das vezes, a aplicação de herbicidas, até o estabelecimento do componente arbóreo e sombreamento, quando estas gramíneas sairão naturalmente do sistema.

Em áreas, em que a aplicação de herbicidas pode comprometer o sistema, o custo de recuperação (devido ao custo de manutenção) é elevado, assim, podemos utilizar a matéria orgânica morta ao redor das mudas. A camada orgânica, colocada ao redor das mudas (coroa), garante a umidade do solo e evita o surgimento de plantas competidoras com as que foram implantadas. Muitos materiais se prestam para formar esta cobertura morta, e, em especial, quando buscamos recuperação ambiental em áreas que estão cobertas por gramíneas (principalmente gramíneas agressivas do tipo braquiária), esta proteção tem papel fundamental. Existe uma grande deficiência na pesquisa de materiais para a formação de camada orgânica morta ao redor das mudas (mulching), esta proteção tem efeitos fantásticos, eliminado custos de manutenção e garantindo o sucesso do plantio. Uma boa opção, na roçada e no coroamento, é colocar toda matéria orgânica, oriunda destas operações, ao redor das mudas, visando manter a umidade do solo e evitar o aparecimento de plantas competidoras ao redor das plântulas introduzidas. A roçada, quando necessária, deve ser realizada em linhas, sempre acompanhando o sentido das curvas de nível do terreno que está sendo recuperado.

No serviço de limpeza inicial do terreno, onde já existe algum tipo de cobertura, esta nunca deverá ser completamente eliminada, pois estas plantas exercem um papel importante na proteção e na conservação dos solos. Deve ser eliminada somente a vegetação que compete diretamente com as mudas plantadas, sendo este controle feito através de coroamento (ao redor das mudas) ou em linhas (nas linhas de plantio). 
o. Bibliografia

p. Anexos - fotos, plantas ou croqui de localização e Anotação de Responsabilidade Técnica (ART), obtida junto ao CREA.

\subsection{Avaliação de PRAD}

No Brasil, esta é uma das atividades que tem muito a evoluir, hoje é necessário treinamento dos técnicos de órgãos ambientais ligados à análise de PRAD, estes devem ser analisados sempre com uma visão mais ampla, observando a interligação entre as partes. $\mathrm{Na}$ análise inicial do PRAD, no escritório, devem ser observadas as informações coletadas na fase de diagnóstico, que devem ser coerentes e utilizadas nas etapas previstas para a recuperação ambiental. Todos os estudos, realizados na fase de diagnóstico, devem ser anexados ao PRAD, permitindo melhor análise. A base para a avaliação inicial do PRAD são as vistorias de campo, onde devem ser conferidas se as estratégias de recuperação, prescritas no PRAD, foram realmente implantadas. Em longo prazo, devem ser exigidos também os relatórios de monitoramento com respectivos pareceres e relatórios de laboratórios, Universidades e Instituições de pesquisa em anexo.

\subsection{Estudos de caso sobre algumas situações específicas}

\subsection{1 Áreas degradadas por mineração}

Principalmente no estado de Minas Gerais, na área de floresta atlântica e transição floresta/cerrado/campos de altitude, a recuperação de áreas mineradas vem sendo praticada há algum tempo. Vários métodos de recuperação e novas tecnologias foram desenvolvidos. Desde a Constituição de 1988, desde que a recuperação destas áreas é obrigatória, muito se tem evoluído neste sentido. As técnicas de telas (metálicas, sintéticas e naturais), hidrossemeadura e outras evoluíram e foram adaptadas para estas situações.

Hoje, todo solo retirado, na fase inicial da mineração, é armazenado durante a fase de lavra, e recolocado depois de terminada 
a retirada do minério. Esta operação facilita o trabalho de revegetação, pois temos o horizonte " $\mathrm{A}$ " presente, facilitando o estabelecimento da vegetação.

O maior problema das áreas após a mineração é a presença de taludes com grandes declives, o que inviabiliza o estabelecimento de muitas espécies; e, na maioria dos casos, esta inclinação não permite a introdução de um componente arbóreo. As empresas estão utilizando, em sua maioria, apenas o plantio de gramíneas e outras espécies herbáceas e espécies exóticas (Pinus e Eucaliptus), poucas estão se preocupando em recompor a vegetação original da área, antes da mineração.

Uma técnica empregada com muito sucesso, neste caso, é o plantio misto de mudas leguminosas herbáceas e arbóreas, fixadoras de nitrogênio atmosférico, de preferência mudas micorrizadas e inoculadas. Na etapa de seleção de espécies, devemos nos preocupar em escolher espécies que nodulem e possam crescer em condições de solos presentes nestas áreas.

\subsubsection{Florestas ciliares}

Ecossistemas de florestas ciliares, também chamados de matas ciliares, florestas de galeria, mata aluvial e florestas ripárias são florestas ocorrentes nas proximidades das margens dos cursos de água. A vegetação característica surge em função de características específicas, presentes nestes ambientes, como: solos típicos aluviais - com elevados teores de umidade, maior umidade atmosférica, temperaturas mais baixas e topografia, variando em função de características hidrológicas e geomorfológicas. Portanto, sob estas condições combinadas, surge uma vegetação típica, com composição florística e estrutura própria.

Por se tratar de um ecossistema com características específicas, quando trabalhamos com estes ambientes, devemos conhecer seu processo sucessional - composição florística e estrutura típica de cada estágio - pois é necessário um projeto específico para florestas ciliares.

$\mathrm{Na}$ área de domínio da floresta atlântica, existem vários trabalhos específicos sobre recuperação ambiental de florestas ciliares. Alguns estados, como Minas Gerais, São Paulo e Paraná já desenvolvem, há muitos anos, programas de recomposição de florestas 
ciliares e de áreas em margens de represas. Estes trabalhos são importantes referências para quem deseja se especializar ou desenvolver um projeto de recuperação destes ambientes. Existem algumas controvérsias quanto à importância das matas ciliares, para alguns especialistas, em hidrologia florestal, a recuperação de topos de morros (área de captação) seria mais importante do que a recuperação de áreas nas margens dos cursos de água. Apesar destas discussões, sabemos que as áreas de florestas ciliares exercem uma importante função tampão, protegendo os rios e influenciando muito a qualidade da água.

A FOTO 15 mostra uma área de mata ciliar bem conservada, presente nas margens do Rio Acaraí, município de Camamu, Bahia, cuja água é utilizada para abastecimento do mesmo município. Nestas áreas de matas ciliares, em bom estado de conservação, as florestas se interagem e protegem os recursos hídricos. A introdução da prática de Pagamento de Serviços Ambientais (PSA) tem como fundamento remunerar proprietários rurais destas margens, que conservam suas matas e rios. Estes proprietários futuramente podem vir a ser remunerados pela conservação destas áreas e já

FOTO 15 - Florestas ciliares em bom estado de conservação, Rio Acaraí, município de Camamu, Bahia

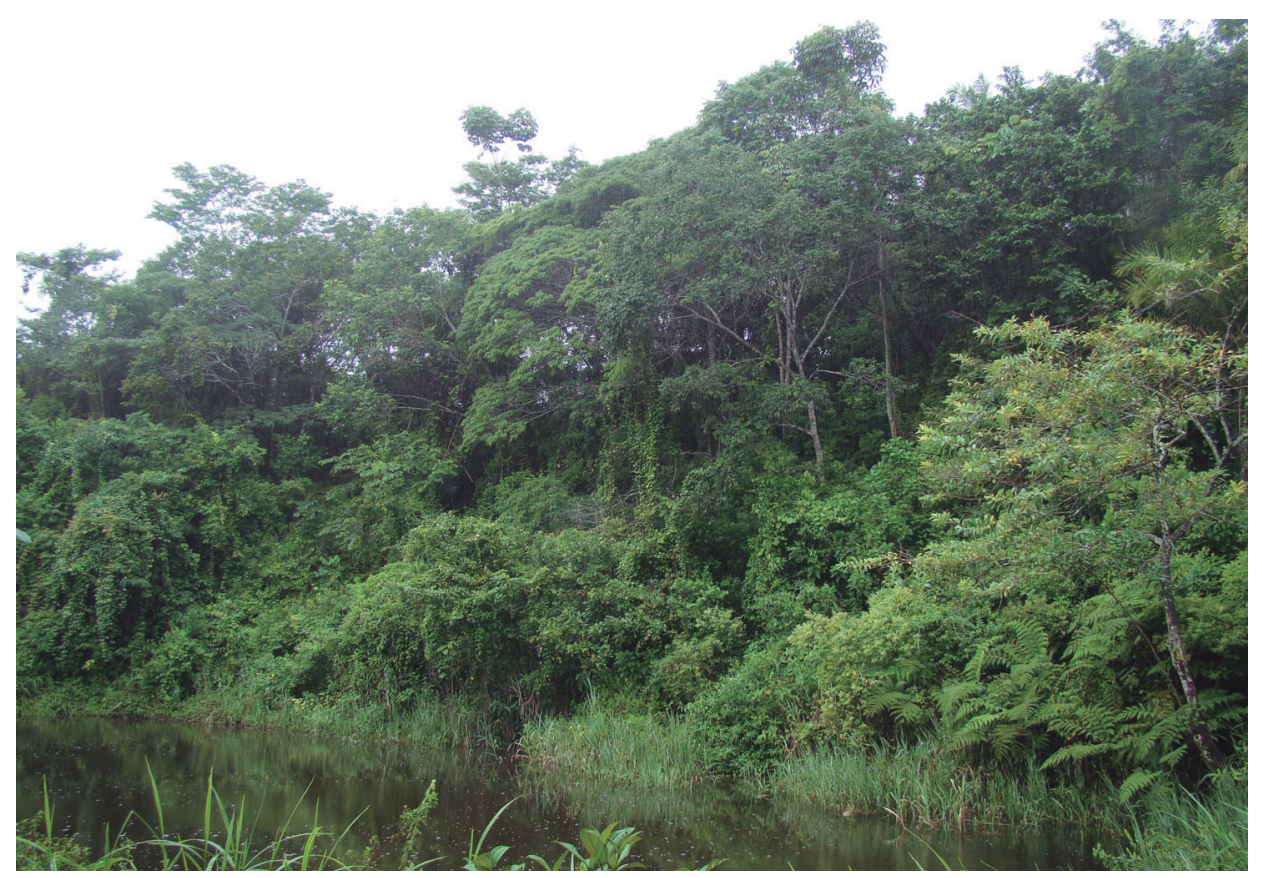


existem vários projetos desta natureza em curso em vários países e, mais recentemente, no Brasil.

10.7.3 Taludes de grandes declives em margens de rodovias

Nas áreas originárias da construção de estradas, em regiões de relevo acidentado, a recuperação destas áreas torna-se indispensável para a segurança dos transeuntes. As estradas, nas quais não são recuperadas áreas inclinadas, estão sujeitas constantemente a interrupção do tráfico, devido ao desmoronamento de encostas sobre a pista de rodagem, causando prejuízos ambientais e econômicos gerais. Além da queda de barrancos sobre a pista, o carreamento de barro para a estrada provoca grande risco de acidentes.

FOTO 16 - Sequência de recuperação ambiental de área de encosta margeando uma estrada. Estrada municipal para praia de Itaquena, Trancoso, Porto Seguro, Bahia
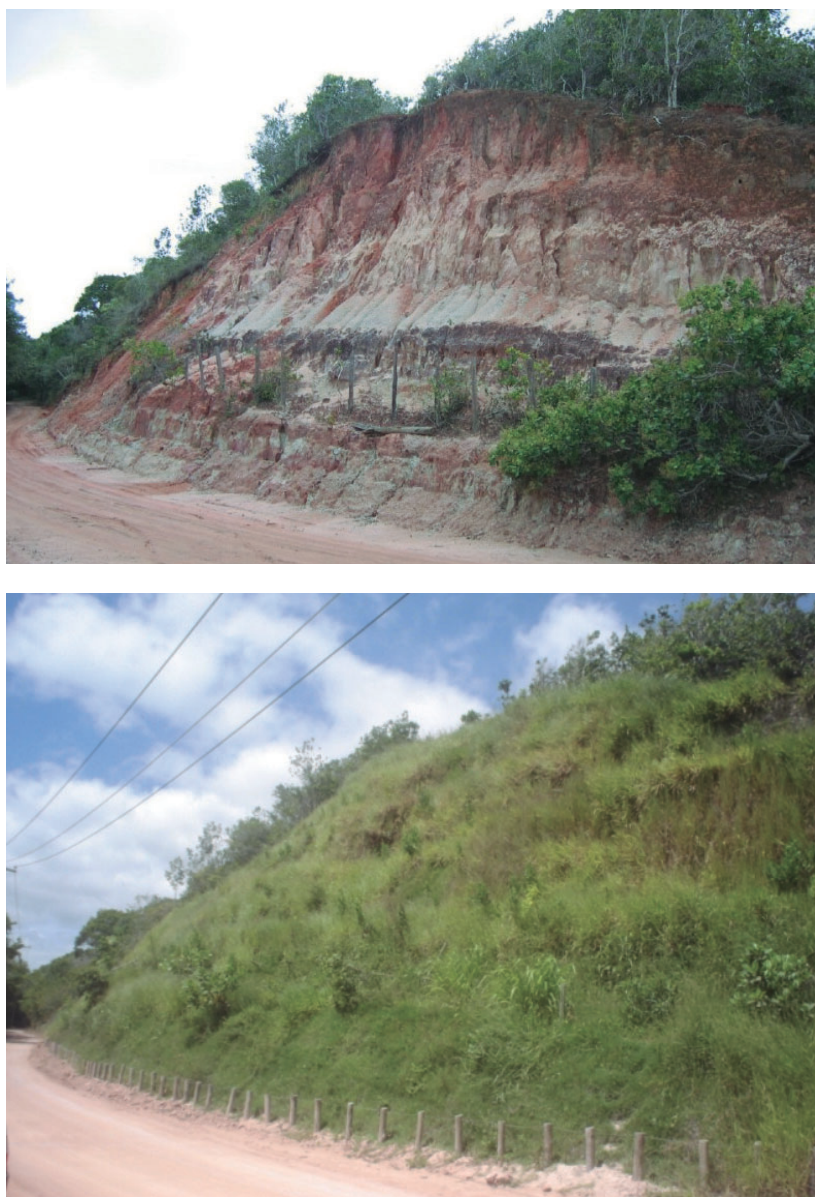
Nestes casos, em função da inclinação dos taludes, geralmente não é recomendável a utilização do plantio de espécies arbóreas na recuperação. Devemos utilizar espécies herbáceas e gramíneas que podem ser plantadas via hidrossemeadura, hidrossemeadura combinada com telas ou mudas e, em função do tamanho da encosta, o plantio direto de mudas. A FOTO 16 mostra a sequência de recuperação ambiental em área de talude na margem de rodovia municipal, estrada da praia de Itaquena, distrito de Trancoso, município de Porto Seguro.

\subsubsection{Erosão em sulco ou voçorocas}

Em função do tipo de solo, com a remoção da vegetação protetora, ele está exposto a uma constante perda de solo. Em áreas montanhosas onde o fluxo de água proveniente de chuvas se concentra em determinados canais, formam-se os sulcos ou voçorocas, que exigem um bom planejamento para sua recuperação. A eficiência do projeto de recuperação destas áreas depende da inclusão de obras de engenharia (construção de canaletas e caixas de drenagem, visando desviar a concentração do fluxo de água e esta-

FOTO 17 - Área degradada de voçoroca em processo de recuperação, através do uso de paliçadas e revegetação com espécies de gramíneas, leguminosas e bambus

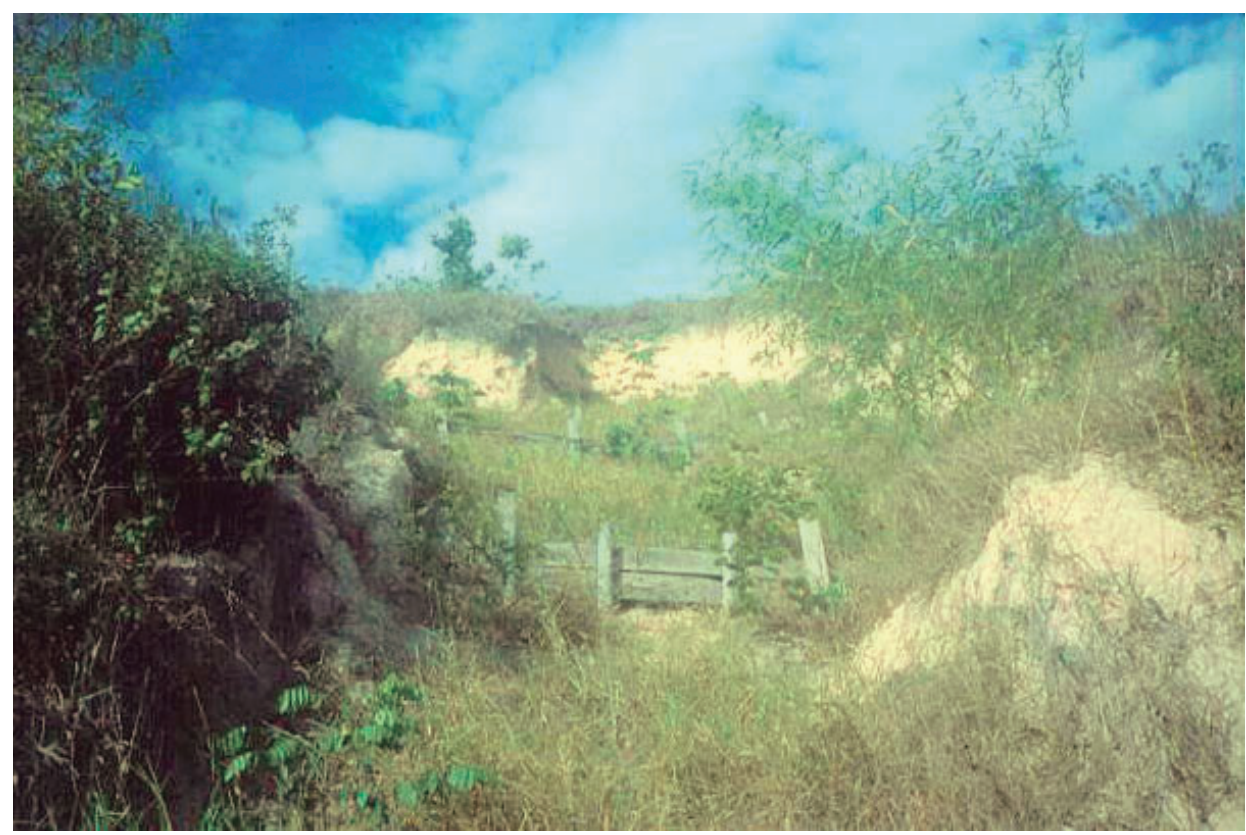


bilizar o canal principal da voçoroca). O uso de sacos de aniagem, paliçadas e outros obstáculos para o aumento do canal principal da voçoroca também são necessários na fase inicial. Somente após a estabilidade física da área, é que partimos para a utilização de métodos biológicos para revegetação e estabilização dos taludes e fundos de voçorocas e sulcos.

10.7.5 Ecossistema degradado pela presença de espécies exóticas invasoras

A presença de espécies exóticas invasoras pode causar degradação em ecossistemas naturais, estas espécies ocupam espaços/nichos, antes ocupados pelas espécies nativas, interferindo igualmente nas relações ecológicas flora/flora, flora/fauna, causando desequilíbrio nas áreas naturais, inclusive a extinção de espécies nativas. Da mesma forma, espécies exóticas da fauna tendem a aparecer nestas áreas.

Para a recuperação ambiental destas áreas, sugerimos a substituição gradual das espécies exóticas por espécies nativas, evitando formar grandes clareiras que poderiam causar impacto no solo destes ambientes. As mudas nativas devem ser reintroduzidas após o levantamento florístico e fitossociológico de áreas naturais similares. O planejamento da recuperação e um bom cronograma de ações são fundamentais para o sucesso da eliminação total das espécies exóticas e restauração com as espécies nativas.

Ressaltamos a importância desta ação especialmente em algumas áreas de restinga e florestais, próximas aos centros urbanos, quando a presença de infestação de espécies exóticas atinge um maior nível. 